\title{
The Circle, from Descartes' Point of View
}

\author{
John H. Dreher \\ University of Southern California Los Angeles, Los Angeles, CA, USA \\ Email:dreher@usc.edu
}

How to cite this paper: Dreher, J. H. (2017). The Circle, from Descartes' Point of View. Open Journal of Philosophy, 7, 201219.

https://doi.org/10.4236/ojpp.2017.72012

Received: January 31, 2017

Accepted: May 28, 2017

Published: May 31, 2017

Copyright $\odot 2017$ by author and Scientific Research Publishing Inc. This work is licensed under the Creative Commons Attribution International License (CC BY 4.0).

http://creativecommons.org/licenses/by/4.0/ (c) (i) Open Access

\begin{abstract}
My project is to show that despite relentless criticism from the beginning, Descartes cannot be reasonably faulted in his attempt to relieve systematic doubt or as it is sometimes called, metaphysical doubt. By "cannot be reasonably faulted" I mean that Descartes is not open criticism either for having made assumptions that were unwarranted by standards of his own time or for having made errors in reasoning. The paper seeks to analyze Descartes' struggle with metaphysical doubt and radical skepticism in relation to issues concerning provability and truth in arithmetic that are addressed by Gödel-Löb provability logic.
\end{abstract}

\section{Keywords}

Descartes, Gödel-Löb, Doubt, Skepticism, Provability

\section{Introduction}

From the very beginning, when Descartes published Meditations on First Philosophy, there were complaints. Gassendi harrumphs at Descartes' argument that because we have a clear and distinct idea of God, there must be a God who would not deceive us, but, Gassendi continues, Descartes nevertheless unreasonably claims that our clear and distinct ideas must be true because God would not allow us to be deceived by them (Gassendi, 1641: pp. 193-195). Even Descartes' sympathetic critic, Arnauld, complains that Descartes concedes that before we can be certain that God exists, we must convince ourselves that whatever we clearly and distinctly perceive is true, but all that Descartes has to offer by way of assurance is that God exists because we clearly and distinctly perceive that he exists (Arnauld, 1641: pp. 145-150). Contemporary philosophers have also found themselves puzzled by Descartes' arguments of the third meditation. Margaret Wilson suggests that Descartes' problem is that he does not limit the scope of his doubt. If we can be deceived about everything, we can be deceived in any argument we give to show that there is a way to relieve our vulnerability to 
deception. Indeed. It is difficult to resist the conclusion that when reason doubts its own ability to reason, it cannot be reasonably reassured by reasoning (Wilson, 1978: pp. 131-136). Bernard Williams takes a different approach, but comes to a similar, dreary conclusion. He does not accuse Descartes of circular reasoning, but rather of flawed "proofs" of the existence of God, which are based upon extravagant metaphysical assumptions that are not convincing when immediately "intuited" and are even less convincing when they are merely recollected (Williams, 1978: pp. 189-204).

In contemporary terms, the Cartesian predicament finds an analogue in formal logic. As Gödel taught, if we try to satisfy ourselves of the truth of Peano's arithmetic (PA), we founder on the shoal that divides provability from truth. Provability in PA does not guarantee truth. Contrariwise, Descartes seems to think that clear and distinct perception does guarantee accurate representation and hence truth. Quite reasonably and naturally, this seems to most contemporary thinkers to be a serious and obvious error. Could it be that Descartes, a mathematical genius as well as the parent of modern Western philosophy, made a silly, simple mistake? This paper argues not. It is mark of Descartes' genius that he intuitively understood the weakness of his position. Surely one can entertain the doubt that all clear and distinct perceptions must be true; however, could one clearly and distinctly perceive of a certain, particular proposition that $i t$ is clearly and distinctly perceived and yet that it is not true? Wouldn't any evidence against the truth of that proposition also count against its having been clearly and distinctly perceived in the first place? One might think so. Descartes thought so. That is why it is, I shall argue, that Descartes was convinced that he could relieve his skeptical doubts to his own satisfaction without circularly. It is also the reason why it is that Descartes should be read as having taken a "meditational" or "confessional" approach in his attempt to relieve metaphysical doubt.

If the paper is successful, it will show that the approach that Descartes took in dealing with his own doubt is just as viable now for us as it was for him. It further shows how important it is for us to distinguish between methodological and substantive claims. Substantive claims always presuppose that the methodology on which they are based. This means that we must approach philosophizing with intellectual humility and a spirit of toleration. The question is not only whether or not a claim can be substantiated but also whether the methodology by which the claim is substantiated can itself be successfully defended.

\section{The Meditational or Confessional Approach}

By taking the "mediational" or "confessional" approach Descartes moderates his claim to relieve his own metaphysical doubt. Descartes intends to include us in his own attempt to ground his philosophical system on principles that he finds to be beyond doubt, but he is not claiming that others who reject his approach are unresponsive to reason, for example because they think of beliefs about God as irrational commitments, or because they fail to accept cogent arguments for beliefs about God. This, I emphasize, is not to say that people who demand more 
from Descartes are making unreasonable or uninteresting demands; it is only to say that they are hoping for more from Descartes than he himself thought that he was in a position to offer. The meditational approach to Descartes has abundant textual justification. For example, in the Discourse on Method Descartes reflects upon his own philosophical method and the standards to which he held himself in argument:

Yet, I may be wrong: Perhaps what I take for gold and diamonds is nothing but a piece of copper and glass. I know how much we are liable to err in matters that concern us, and also how much the judgements of our friends should be distrusted when they are in our favour. I shall be glad, nevertheless, to reveal in this discourse what paths I have followed, and to represent my life in it as if in a picture, so that everyone may judge it for himself; and thus, learning from public response the opinions held of it, I shall add a new means of self-instruction to those I am accustomed to using. My present aim, then, is not to teach the method which everyone must follow in order to direct his reason correctly, but only to reveal here how I have tried to direct my own (Descartes, 1637: p. 112).

Descartes wrote during the period of the Spanish Inquisition and the Thirty Years War, perhaps the most dreadful period in European history, setting aside the last days of Rome and the early twentieth century. This has led some people to think that Descartes might not have been completely ingenuous in his philosophical writing. Perhaps he affirmed his religious beliefs, in particular his arguments for the existence of God, to protect himself from the Inquisition or even to ingratiate himself with the Sorbonne elite in order to advance his career. I believe that this view of Descartes' motivation is incorrect, and I assume throughout that Descartes means exactly what he writes in his Dedicatory letter in Meditations on First Philosophy to the Sorbonne.

I have always thought that two topics-namely God, and the soul-are prime examples of subjects where demonstrative proofs ought to be given with the aid of philosophy rather than theology. For us who are believers, it is enough to accept on faith that the human soul does not die with the body, and that God exists; but in the case of unbelievers, it seems that there is no religion, and perhaps no moral virtue, that they can be persuaded to adopt until these two truths are proved to them by natural reason. Although it suffices for us believers to believe by faith that the human soul does not die with the body, and that God exists, certainly no unbelievers seem capable of being persuaded to any religion or even of almost any moral virtue, until these two are first proven to them by natural reasons (Descartes, 1641: p. 3).

Here we find that Descartes distinguishes philosophical (natural) theology from revealed theology. He grants that most in the way of religious doctrine is a matter for revealed theology and involves what he calls "belief by faith". However, Descartes claims that philosophy is necessary when it comes to certain religious beliefs, and that those who are "unbelievers" will never come to religious 
faithunless they are satisfied that the existence of God and the immortality of the soul have been proved to them by natural reason.

Let me acknowledge at the outset that although I take the meditational approach in interpreting Descartes, I concede that there is textual evidence against this approach (for example in the above quotation from the Dedicatory letter to the Meditations), and therefore there will be much for me to explain. In the quotation above, Descartes announces that he cannot reach his goal of converting unbelievers until "these two [that the human soul does not die with the body, and that God exists] are proved (my emphasis) to them by natural reason". Moreover, immediately preceding the first meditation, Descartes offers the following bold "advertisement" of his work: MEDITIATIONS ON FIRST PHILOSOPHY IN WHICH THE EXISTENCE OF GOD AND THE DISTINCTION BETWEEN THE SOUL AND THE BODY ARE DEMONSTRATED. The words "proved" and "demonstrated" support the standard view that Descartes is aiming to find out the truth and that he thinks that he has found it, but that is not what I dispute. What I dispute is the further claim that Descartes thinks that what he accepts as a demonstration others are also compelled by reason to accept. It is true that if one (including Descartes) claims to have demonstrated a mathematical truth like the Pythagorean Theorem, one is in effect claiming that those who disagree are in error. But Descartes does not claim that about his 'demonstration' of the existence of God. He claims to have satisfied himself, but does not claim that those who doubt or disagree are irrational or unreasonable. In the Preface, preceding the "advertisement" above, Descartes writes:

I will set out the very thought which have enabled me, in my view, to arrive at a certain and evidence knowledge of the truth, so that I can find out whether the same arguments which have convinced me will enable me, in my view, to arrive at certain and evident knowledge of the truth, so that I can find out whether the same arguments which have convinced me will enable me to convince others (Descartes, 1641: p. 8).

This is certainly not what one would say who was demanding assent by the force of logic. Can you imagine reading a statement in anintroduction to calculus by an author who claims to offer arguments in the hope that they will also convince others? Arguments that end in quod erat demonstradum do not request but demand assent; they are like the last moves in a chess game that inexorably ends in mate. Descartes' claim for his "proof" of the existence of God is qualified. Descartes has no doubt that he has presented a demonstration of particular propositions, like the proposition that God exists, but that does not mean that he is assumes much less demands that others must agree because they are compelled to agree by inexorable, irrefragable logic.

\section{Radical, Metaphysical Doubt}

Descartes begins his meditations by casting aside or "considering as false" all the beliefs that he had previously accepted. This has led to a worry, that in setting 
aside his beliefs "as false" he must have accepted their negations as true. But this criticism is at least uncharitable and arguably incredible. Descartes at this point is resolving to hold all his previous beliefs in abeyance, unless they can meet a certain standard. ${ }^{1}$ That standard is revealed to us in the supposition of the evil demon, who, Descartes proclaims, "may deceive [him] at every point", but that is not to say that Descartes thinks that the evil demon supposition gives him, Descartes, sufficient reason to think that every belief that he ever held is false.

No sooner does Descartes raise his conjecture of metaphysical doubt, than he claims to have discovered a judgment that is beyond all doubt, a belief about which he could not be deceived even by the evil demon. It is of course the " $\mathrm{Co}$ gito", as it is called. Descartes proclaims that this proposition: “I am, I exist' is necessarily true each time I think or pronounce it to myself". The Cogito has been the subject of innumerable interpretations. It is obviously meant to be self-validating in some sense. What is important for our purposes, however, is the simple point that Descartes is satisfied that the proposition is true and that it is safe from the evil demon. Notice, however, if someone were simply and flatly to deny the claim, Descartes would have nothing to say in response. He has claimed only that the Cogito is beyond his own doubt. Yet, he never claims to prove anything to anyone else, and he hardly ever claims that those who disagree with him are being stubborn or perverse in their denials. He only is telling us that he is satisfied that the Cogito has passed the test that he set for himself.

\subsection{The Distinction between Demonstration and Intuition}

In the Introduction to Descartes Conversation with Burman, which has been a part of the literature for 50 years, Cottingham emphasizes the importance of intuition in Descartes' understanding the Cogito (Burman, Descartes' Conversation with Burman (1648), John Cottingham, Trans., 1976, p. xx.; Cottingham, Stoothoff, \& Murdoch, 1985). Descartes is aware that if the Cogito were interpreted as a demonstration, the obvious follow-up would be to show how the premises of the argument are known in light of the doubt raised by the supposition of the evil demon. Cottingham argues that Descartes must think that the Cogito is affirmed not on the basis of demonstration but rather of intuition. I am not sure that Cottingham is right about this, but it is a simplifying assumption in interpretation, and I think that something can be made of it.

In this respect, the next step in the argument for Descartes is very important, although it seems to me that its upshot is underappreciated in much of the literature. If Descartes has satisfied himself that he exists, the obvious question is just who or what he is. Descartes concludes that he is a thing that thinks, a thinking thing. What proves that he is a thinking thing?-It is the fact that his thinking "demonstrates" his existence-but what sort of demonstration (or intui-

\footnotetext{
${ }^{1}$ It is true that Descartes sometimes "supposes" that everything that he believed is false, but that supposition is for the sake of the argument that results in the Cogito, and should not be read as implying that Descartes' standard is to show that literally everything he once thought true is actually false. It should read it is in this way: Suppose that everything that I once thought true and which I can now doubt is actually false.
} 
tion) could that be? Perhaps for Descartes it is just that his thinking reveals or makes him aware of his own existence, and it is in this sense that Descartes' existence as well as his nature may be revealed by (or perhaps in) intuition. In this thought experiment it appears that a certain "mental act" or experience reveals a fact. It is thinking that he exists, which reveals his existence, and it is his thought that his thinking reveals his existence that defines his nature, which is to think. Descartes writes:

Thought alone is inseparable from me... I am in the strict sense only a thing that thinks... I am a thing which is real and which truly exists. But what kind of a thin? As I have just said-a thinking thing (Cottingham/Descartes, VOL II, 1641: p. 18, \$27).

\subsection{The Role of the Imprint Theory of Causation}

At this point in Meditations a general, metaphysical principle comes to mind: That whatever explains the existence of a thing, also explains its identity. This is a version of the Imprint Theory of Causation (ITC). ITC is the linchpin of early modern rationalist metaphysics. It is, for example, what Hume later is at pains to deny when he insists that the effect can never be discovered in the cause. I think that it is undeniable that Descartes considers himself licensed to draw inferences about the nature of a thing from whatever demonstrates or reveals its existence. That does not mean, however, that Descartes has claimed that he has shown that everyone must accept this metaphysical principle. I believe that the final line of the passage above indirectly supports a meditational or confessional reading. It is not as though Descartes concludes his argument that he is a thinking thing with "quod erat demonstrandum"; rather he concludes his argument by repeating his testimony: He writes merely: “As I have just said; a thinking thing”. Descartes knew when he had produced an obviously sound argument that every rational mind must accept, and if he had thought that he had produced an obviously sound argument that we all must accept lest we be deemed uniformed, stubborn or dull; he wouldn't have ended his argument so humbly.

Descartes views the mind as a created substance, and he thinks of ideas as modifications of the mind. For Descartes coming to "have" certain ideas (innate ideas) is a matter of becoming aware of what is already in the mind, that is, what is already a characteristic of the mind-a mode of it. The process of becoming aware is essentially a matter of thinking; so in becoming aware of ourselves we are becoming aware of an idea that each of us already has, but of which we have hitherto been unaware. According to Descartes, he can think not only of himself but also of God: But just who or what is God? Descartes claims to perceive clearly and distinctly that the idea of God is an idea of something that is eternal, self-caused and simple. The key idea is that God is eternal; from it will follow by clear and distinct reasoning that God is simple and self-caused and hence that God exists. Yet, the argument is long and in places torturous. Let us assume for the moment that Descartes can make out the case that he has a clear and distinct idea of God and that God is a being who is simple, eternal and self-caused. As- 
suming that we have such an idea, it follows according to Descartes that the idea must have a cause that is adequate to explain both its existence and the identity of its effect. This is in effect a consequence of the ITC, which itself plausibly follows from the ancient, plausible doctrine: ex nihilo, nihilo fit. That thing, which causes our idea of God must be up to the task, rich enough to explain both the cause and the identity of the idea of God; that thing must be God, the only thing it could be, and therefore it must be that God exists (For the step-by-step reconstruction, see Appendix A).

Now it is easy to see where the worry about the "Circle" arises. Descartes claims to have certain clear and distinct perceptions; ${ }^{2}$ however, his argument for the existence of God will go through only if his clear and distinct perceptions are true. ${ }^{3}$ That is, if they are accurate representations, which is precisely what the famous Truth Principle asserts. Descartes himself acknowledges that he can be satisfied that the Truth Principle is itself true only if the evil demon has been defanged, but how can Descartes then rely upon the Truth Principle to defang the evil demon? Descartes' critics are right to remonstrate that he cannot without viciously circularity argue that he is not deceived about the Truth Principle by the evil demon because God exists, and the judgement that God exists must be true because we have a clear and distinct idea of a self-caused entity that could only be caused by that very same self-caused entity, and finally that his own clear and distinct judgments about all this must be true in light of the Truth Principle.

Even so, there is also something that the critics miss, which is that there is something very important that Descartes can claim, and that is that he clearly and distinctly perceives the Truth Principle. The heart of the argument for that claim is that there is nothing that could be counted by Descartes as a reason for disbelieving the Truth Principle. How could anyone have a reason for thinking that he clearly and distinctly perceives both that $p$ and yet that $p$ is not so? For Descartes: Anything counting as a reason for disbelieving that $p$ will also count as a reason for doubting that the perception that $p$ is clear and distinct. That is why it is that Descartes set his famous rule for himself: To accept that and only that which he clear and distinctly perceives. Descartes concludes that he clear and distinctly perceives the Truth Rule: That whatever he clearly and distinctly perceives is true. (For the step by step reconstruction, see Appendix B).

\subsection{Descartes' Deflationary Move}

It will be objected, no doubt, that Descartes is getting away with conceptual-

\footnotetext{
${ }^{2}$ Cottingham convincingly argues that Descartes worries about memory precisely because he anticipates a possible objection that even if he proves the existence of God, doubt will arises over and over because we might not be certain of our memory of the proof of the existence of God that ultimately relieves metaphysical doubt. However, if our proof of the existence of God is intuited, then Cottingham argues, we need only recall the intuition, and observe that it is clear and distinct, to once again satisfy ourselves of our capacity for knowledge. (Burman, Descartes Conversation with Burman (1648), John Cottingham, Trans., 1976: p. 58f, pp. 58-60).

${ }^{3}$ Descartes' argument could be attacked in a different, equally important way. One might concede that every clear and distinct idea is true, that is an accurate representation, but then deny that Descartes clearly and distinctly perceives what he claims to clearly and distinctly perceive. Indeed, in assessing metaphysical doubt, it will be necessary to deal with both issues.
} 
murder. After all, he can claim to clearly and distinctly perceive whatever he pleases, and as long has he qualifies his conclusions by limiting them to what to what he clearly and distinctly perceives, no one will be able to refute him, because all that Descartes claims to do is to show us "how [he] has conducted [his] own [reason]". He never claims to show us how we must conduct our own reason. The meditational reading of Descartes deflates our legitimate expectations of Descartes. Yet that is precisely why it is that the circularity objection, understandable though it is, is misguided and even uncharitable. Descartes' principal goal is to offer a demonstration of the existence of God and the real distinction between mind and body, but he can relieve himself of the doubt that his demonstration is genuine, that is sound, only if he can relieve himself of doubt about whether every clear and distinct perception is true. One way to do that would be to prove that every clear and distinct perception is true, but Descartes cannot do that without entrapping himself in circular reasoning, immobilized, as it were, in the ninth circle of epistemological hell. Even so, he can relieve himself of the doubt that every clear and distinct perception is true, because he without a doubt has a clear and distinct perception that whatever he clearly and distinctly perceives is true. That is the point of Appendix B. Of course, Appendix B does not prove that every clear and distinct perception is true, but Descartes does not claim that he has proved that. Rather he asks others to give his "method of reason" a chance; a chance to see whether or not they can doubt what they clearly and distinctly perceive is true. If others give the Cartesian method a chance and conclude that clear and distinct perception is not a mark of truth, there is nothing that Descartes can say. Perhaps that would be enough to convince some that Descartes not have very much to say, but if that is true, then, as we shall shortly see, neither does Peano's Arithmetic have very much to say.

\section{An Analogy to Gödel-Löb Provability Logic}

Now it is time to see what we can learn from how Descartes conducts his own reasoning. I want to focus on the most basic issue, which is the relation between clear and distinct perception, doubt and truth. I am going to argue that in contemporary terms, the Cartesian predicament finds an analogue in formal logic. As Gödel taught, as we try to satisfy ourselves of the truth of Peano's axiomatization of arithmetic (PA), we founder on the shoal that divides provability from truth. This has given rise to so-called provability logics, including Gödel-Löb logic; henceforth "G-L logic".

To begin, two basic principles of the standard alethic modal logic S2 are:

$$
\boldsymbol{K}: \square(\boldsymbol{p} \rightarrow \boldsymbol{q}) \rightarrow(\square \boldsymbol{p} \rightarrow \square \boldsymbol{q}),
$$

and

$$
\square \boldsymbol{M}: \square \boldsymbol{p} \rightarrow \boldsymbol{p},
$$

where " $\square$ " is read: it is necessary that.

Now, switching gears, where “ $\square$ " is read: it is provable that: 
$K$ still appears to be reasonable with respect to PA, but, as Gödel demonstrated, $\square \boldsymbol{M}$ is false of PA; that is, there are propositions that are provable but not true. Now, G-L doesvalidate $K$, but what to do about $M$ ? $M$ is replaced by a deflationary principle that I shall call

$$
\boldsymbol{G}-\boldsymbol{L} \square \boldsymbol{M}: \square(\square \boldsymbol{p} \rightarrow \boldsymbol{p}) \rightarrow \square \boldsymbol{p} .
$$

AsGödel demonstrated: Just because something is provable in PA does not guarantee its truth; however, if it is provable that $p$ is provable only if $p$, then it is reasonable to conclude that $\boldsymbol{p}$ is provable (Van Benthem, 2010: p. 244ff).

In fact, the logic that I am about to attribute to Descartes includes the Cartesian analogue of $\boldsymbol{G}-\boldsymbol{L} \square \boldsymbol{M}$, which I call:

$$
D C_{i} \square M . D C_{i}\left(D C_{i} p \rightarrow p\right) \rightarrow D C_{i} p^{4},
$$

where "DC" abbreviates "Descartes clear and distinct", or henceforth, "Descartes-provable". This principle, says from Descartes point of view. If it is Descartes-provable that $\boldsymbol{p}$ is Descartes-provable only if $\boldsymbol{p}$, then $\boldsymbol{p}$ is Descartes-provable. But what does "Descartes-provable" mean? This system, to be developed in the next paragraphs, which I call $D C_{i} \square M$ and $D C_{i} S 4$, are merely analogues of their $G-L$ counterparts because $D C_{i}$ contains the indexical " $i$ " as a subscript. " $\boldsymbol{D C} \boldsymbol{C}_{i}$ " can always be read "I clearly and distinctly perceive". That is how Descartes would have read the statement himself, and this paper is written from Descartes point of view.

Now, consider the Truth Principle T, which is that everything clearly and distinctly perceived is true; it is itself arguably beyond the doubt of anyone who claims to clearly perceive that it is a guarantor of truth. The justification for this claim is that anything that I would count as a reason for disbelieving or doubting that $\mathrm{T}$ would also count as a reason for doubting or disbelieving that I clearly and distinctly perceive that $\boldsymbol{p}$ only if $\boldsymbol{p}$ is true. (For the step by step details, re-visit Appendix B). What this shows is that Descartes cannot have a reason for doubting whatever he clearly and distinctly perceives is the true, if he clearly and distinctly perceives it. And that is precisely what Descartes does claim.

By the same sort of reasoning, Descartes might have satisfied himself of

$$
D C_{i} K: D C_{i}(p \rightarrow q) \rightarrow\left(D C_{i} p \rightarrow D C_{i} q\right)
$$

What could Icount, at one and the same time, as a reason for doubting that I clearly and distinctly perceive $q$, but in favor of my clearly and distinctly that $p$ and clearly and distinctly perceiving that $q$ if $p$ ? Finally it seems reasonable to af-

\footnotetext{
${ }^{4}$ That implies that nothing can be carried over from $G-L$ to $D C_{i} \square M$ or $D C_{i} S 4$ in a straightforward way; that is without a pronominal reference. As argued extensively above, Descartes always refers to himself explicitly or implicitly in order to relativize his assumptions to his own intuitions, that is, to those of his own clear and distinct ideas that he deems to be clear and distinct. The parallel between provability and Descartes provable is obvious, and the obvious point of similarity is what is important here, namely that clear and distinct perception as well as provability are proof-theoretic notions, and that it is always an open question whether a "proof" (that is a sequence proportions that follow each other by the "rules"), will lead to a true conclusion, and if it is does, whether we can know that is does.
} 
firm:

$$
\left(D C_{i} S 4\right)\left(D C_{i} p \rightarrow D C_{i} D C_{i} p\right)^{5}
$$

Justification settles into the preceding template, that is, (from Descartes' point of view) whatever I count as a reason for doubting that I clearly and distinctly perceive that I clear and distinctly perceive that $\boldsymbol{p}$ will also raise a doubt about the claim that I clearly and distinctly perceive that $p$. In other words, if Descartes cannot reasonably claim that he clearly and distinctly perceives that he clearly and distinctly perceives that $p$, he will have absolutely no reason to think that he can be confident that any "perception" is clear and distinct.

There is another complication, which is noted previously in fn. 3 below. If clear and distinction perception is deemed to be a mark of truth, which Descartes does claim, then how can he be so easily satisfied with his intuition that he does clearly and distinctly perceive? $G-L$ provability logic suggests an answer, which is: $\boldsymbol{G}-\boldsymbol{L} \square \boldsymbol{M}: \square(\square \boldsymbol{p} \rightarrow \boldsymbol{p}) \rightarrow \square \boldsymbol{p}$, where " $\square$ " is read "is provable". What we can prove is that a proposition is provable if we can prove that it is true if it is provable. This axiom of $G-L$ logic has a Cartesian analogue, which says that $\boldsymbol{D C} \boldsymbol{C}_{i}\left(\boldsymbol{D} \boldsymbol{C}_{i} \boldsymbol{p} \rightarrow \boldsymbol{p}\right) \rightarrow \boldsymbol{D C} \boldsymbol{C}_{i} \boldsymbol{p}$. This claims that any proposition $\boldsymbol{p}$ is Descartesprovable if it is Descartes-provable that $\boldsymbol{p}$ is the case (true) if it is Descartesprovable. So, assuming that Appendix B is correct in showing that $\mathrm{T}$ is Descartes-provable (clearly and distinctly perceived) only if $\mathrm{T}$ is true, we may conclude, as Descartes does, that $T$ is Descartes-provable, that is that he clearly and distinctly perceives $T$. Further, assuming that $T$ is Descartes-provable, and the rest of Appendix A is Descartes-provable, it follows that the conclusion of Appendix A is Descartes-provable, which is the proposition that God exists.

Now, we have learned to live with Gödel-Löb on the grounds that there really is a connection between provability and truth, although it is weaker than we might have supposed. Indeed, all we can do to satisfy ourselves about the truth of a proposition of arithmetic is to prove it. And $G-L$ logic says that we can be satisfied, that a proposition is provable if only it is provable that its provability entails its truth. Can we say the same for Descartes provability? Maybe; maybe not.

Someone might argue that provability in arithmetic is one thing, provability in metaphysics is another. After all, Descartes provability is "clear and distinct perception", which seems to be a weaker standard than arithmetic provability (although Descartes, who held himself to the standards of mathematical reasoning even in philosophy, might have bridled at the insult). In any case, Descartes has instinctively anticipated the worry. He acknowledges as clearly as anyone could that what has seemed to him to be "gold and diamonds is perhaps nothing buy copper and glass". He is not claiming that we must be satisfied because he is satisfied. He acknowledges that the very arguments that satisfy him might not satisfy us. That is why we must give Meditations a meditational or confessional ${ }^{5}$ Incidentally, the counterpart of (DC $\left.S 4\right)$ in $G-L, \square p \rightarrow \square \square p$, is intuitively correct since the fact that a proposition is provable is itself provable. 
reading; otherwise we are forced to attribute the view to Descartes that we must take Descartes-provability as our own. ${ }^{6}$

But what should we say of Descartes? Shall we say that he is too easily satisfied or perhaps that he is just weak-minded? These conclusions are, to my way of thinking, abhorrent and absurd. We are not talking here about an "everyday" philosopher, we are talking about one of the greatest mathematicians in Western history and arguably the father of modern Western philosophy. The idea that Descartes made a silly mistake, or that he didn't have the courage of his convictions seems to me to be preposterous. So, what then can we say for Descartesprovability?

Imagine a very simple problem from mathematics. Consider the equation: $5^{*} \boldsymbol{x}^{1 / 4}=\boldsymbol{x}^{1 / 2}$. Solve for $\boldsymbol{x}$. Now it is obvious that we ought to be able find $\boldsymbol{x}$ without difficulty. After all, there must be some way to get rid of $\boldsymbol{x}$ on one side of the equation. But what is the way? In his conversation with Burman, Descartes suggests that the way to make progress in thinking about things of this sort is to accustom oneself to the underlying strategies for reasoning well in mathematics by cultivating the right habits of mind. In the case of the equation above, the solution is obvious once we raise each side of the equation to the fourth power. That yields the result $5^{4} * x=x^{2}$; dividing each side by $x$ yields the result that $5^{4}=x$ and therefore $625=x$. People whose high school mathematics is a bit rusty might struggle with the equation, but anyone can see that it ought to be solvable; that is, it ought to be provable. That means that there is a procedure to go through that will yield a result; a true result. This confidence is validated by $G-L$ provability. But can the same be said for Descartes-provability? We are confident that we can come to have clear and distinct idea of the solution to the equation just because we are confident that there is an answer to the question that is based upon a clear and distinct understanding of how true things are proved in algebra. Can we make a similar claim for metaphysics; for "proofs" of the existence of God?

I think that Descartes' answer is affirmative. To illustrate and simplify the exposition I shall refer to a related context, which needs to be addressed in any case. I'll say a word about the proof of the existence of God found in Meditations $V$. If I (or you) conceive God as a being whose existence is necessary, and if I am convinced that if my idea of God is clear and distinct then it must accurately represent (that is be true), then indeed I am justified by $\quad \boldsymbol{D} \boldsymbol{C}_{i} \square \boldsymbol{M}$ in concluding that my idea of God as a necessary existent is clear and distinct. Yet, this also shows just where and why so many resist Descartes. Are we really convinced both that our idea of God as a necessary existent is clear and distinct and that if that is so, it must accurately represent? Most of us would deny one or other of the claims; some would deny both. But what then should we say about Des-

${ }^{6}$ By the way, this illustrates an important point in meta-philosophy, which is that sometimes the same goal can be achieved either pragmatically or semantically. Descartes pragmatic qualifications, the "meditational or confessional approach", now are made semantically in $G$ - $L$ logic, by downgrading $\boldsymbol{M}$ to $\square M$. The same, I claim, can be said for $D C_{i} \square M$. 
cartes? Perhaps Descartes wondered whether or not his idea of a necessary existent really is clear and distinct. On the other hand, perhaps on the basis of his mathematical habits of mind, he concluded that he clearly and distinctly perceives that clear and distinct perception of God is a mark of truth; and therefore that God exists. But then (following the Cartesian analogue of $\boldsymbol{G}-\boldsymbol{L} \square \boldsymbol{M}$, (viz. $\left.D_{C} \square M\right)$ Descartes would be quite justified in concluding that his own idea of God as a necessary existent is clear and distinct. And according to Descartes' own standard (on the mediational or confessional approach), he would have been justified in concluding that he clearly and distinctly perceives that God exists, where clear and distinct perception is a kind of provability that includes the implication of truth.

Some may continue the remonstration; they may claim that Descartes really does not live up to his own standard. What, they may ask, could a necessary being be, and how could any idea of a necessary being be clear and distinct especially if clarity and distinctness do entail truth? Indeed, what could Descartes say? Surely that metaphysics can be as certain as arithmetic, and that its certainty will become apparent only to those who work hard enough. Many great philosophers, like Gassendi and Hume will object, insisting that the idea of a necessary existent is inconsistent. But Descartes is not claiming that their ideas of necessary existents are not inconsistent; he insists only that his own are clear and distinct.

\subsection{Descartes' Point of View}

All this is meant to show that Descartes in not engaged in a weird, anomalous method of reasoning. Descartes illustrates the epistemological predicament in which we all find ourselves, which is that we are always drawing inferences about objective, factual reality that are based upon an internal state that is arguably subjective. Of course, Descartes did not think that his internal state of selfproclaimed clear and distinct perception is subjective-he thought that it is indicative of objective truth, but we can hardly resist asking: How could he? It is tempting to think that in relieving his skeptical doubts about reason Descartes could only have held a grandiose conception of his own thought, or perhaps that he had reasoned in a circle, or at least that he had accepted implausible metaphysical principles. Yet, I hope to have convinced you that he did not reason in a circle because he has assured himself of the Truth Principle by the reasoning exhibited in Appendix B. ${ }^{7}$ As for his metaphysical principles, I think that these too ${ }^{7}$ As conceded, it is natural to complain about this assertion because Descartes rarely draws conclusions that are qualified by "I clearly and distinctly perceive" but it would have been unnatural for him to qualify every conclusion in this way. By way of analogy, one does write "I believe" in front of every assertion. We all assume that an author believes what is asserted unless the assertion is qualified to the contrary. Descartes tells us explicitly that he is showing us his method of reason, and that clear and distinct perceptions revealed or discovered by it. There is no need for him to write "I clearly and distinctly perceive" before every conclusion he draws. Charitable readers surely will grant him that much. Indeed, it would have been odd (though true) for Descartes to have announced at outset that the existence of God and the distinction between the soul and the body would demonstrated by what he (Descartes) clearly and distinctly perceived to be a demonstration but which he could not could not demonstrate is an irrefragable demonstration. 
must be measured in the context of their time. Given ITC, which is not prima facie unreasonable, ${ }^{8}$ the other principles Descartes held seem to be plausible, at least by the standards of his time If all that is true, why then do we resist the Cartesian model? Surely we are not prepared to accept the proof of the existence of God found in Mediations III, but if the argument is not circular and the purportedly necessary metaphysical principles are reasonable by the standards of Descartes' time, then mustn't they, as philosophical principles, be reasonable for all times, including our time? If not- and here is the unexpected turn, what reason do we have we to reject Descartes's crucial metaphysical principles. Exactly what has changed?

\subsection{What Has Changed?}

What has changed is that the paradigms of clear and distinct ideas from the seventeenth century now appear to be mutilated, confusing and false. Descartes thought a clear and distinct perception is a kind of provability, licensing inferences from intuitions, but it does not seem that way to us. Why? The answer lies in the progress of science and the way in which it has undermined (what we now regard as subjective) standards of truth. Thus the analogy between provability and clear and distinct ideas appears to unravel as we watch

$\boldsymbol{D C} \boldsymbol{C}_{i} \boldsymbol{M}\left(\boldsymbol{D C} \boldsymbol{C}_{i} \square \boldsymbol{p} \rightarrow \boldsymbol{p}\right)$ fall apart. In other words, although we agree to the $\boldsymbol{G}-\boldsymbol{L}$ analogue that $\boldsymbol{D C}_{i}\left(\boldsymbol{D} \boldsymbol{c}_{i} \square \boldsymbol{p} \rightarrow\right) \rightarrow \boldsymbol{D} \boldsymbol{c}_{i} \boldsymbol{p}$, we deny that we ever satisfy the antecedent. We do not clearly and distinctly perceive of any significant metaphysical proposition that the fact of our clear and distinct perception of it is adequate for its truth. We have been tricked too many times. In particular we deny $\boldsymbol{D C} \boldsymbol{C}_{i}\left(\boldsymbol{D} \boldsymbol{C}_{i} \boldsymbol{T} \rightarrow \boldsymbol{T}\right)$. Provability is different from clear and distinct perception because we do not doubt provability even if we believe that it is separated from truth (as in arithmetic), but we do doubt clear and distinct perception if we believe that it is separated from truth. If clear and distinct perception is subjective, and arithmetic provability is objective, Descartes now must bear the insult silently. Well perhaps not quite silently, if his admirers remonstrate in his place. In the next section, "Conclusion", I will give Descartes the last word, from his point of view of course.

The main crack in the Cartesian wall first appeared with Einstein's rejection of the application of the fifth of Euclid's postulates to physical space. The idea of a priori knowledge of Euclidean space (and "Augustinian" time) now seems as far away as Aristotle's theory of terrestrial and celestial motion, even though it still intuitively seems as clear now as then that physical space and time really are Euclidean and Augustinian. Yet we are convinced that Einstein showed us that the fundamental unit of event separation is the interval, some units of which are "space-like" and some "time-like". What seemed to be a clear world-view to Descartes now is thought to be a fundamental misconception of the nature of space and time, a misconception of what once was deemed to be clear and dis-

${ }^{8}$ Well, ITC was prima facie reasonable in Descartes' time, but for us causation is essentially statistical and the debates and distractions of the early modern period concerning causation are badly worn, but that does not show that they were badly worn at the beginning of the scientific revolution during the early modern period. 
tinct and therefore indubitable. Besides, even arithmetic theorems, which Hobbes and Hume counted as knowledge because they are "reckonings", turn out to be problematic, just as Gödel showed. I maintain, however, none of this goes to show that the early modern rationalists argued in circles or that their metaphysical principles are unintelligible. ${ }^{9}$ The problem with rationalist metaphysics for us is that we really do not believe that there is a special form of cognition, clear and distinct perception, which is the measure of truth. The lesson to be learned from the fall of rationalism is not that we are right and they were wrong about metaphysics, but rather that human "knowledge" is not a competent judge its own limits, at least as far as we are concerned; which is to say: at least for now. However, we can say that from Descartes' point of view, he was right to be satisfied with clear and distinct perception, just as we are right to be satisfied by provability within $G-L$ logic. Descartes did not engage is circular or silly reasoning, and the premises of his arguments were reasonable metaphysical principles by the standards of his own time.

\section{Conclusion}

I have argued that Descartes is in a stronger position if he holds to his meditational or confessional approach than if he takes the bolder course, insisting that his arguments for the existence of God mimicmathematical proof, arguments that are right to end with quod erat demonstrandum. On that approach, Descartes needs to convince himself that 1) he clearly and distinctly perceives that God exists, 2) that the fact that he clearly and distinctly perceives that God exists proves that God does exist. But along comes trouble. Whether the demonstration takes the form of the argument drawn from Meditations III (Appendix A) or the ontological version of Meditations $\mathrm{V}$, Descartes needs to convince himself of the Truth Principle. Nevertheless, Descartes' instinctive caution saves him, it is the same instinctive caution that is captured at the semantic level by $G-L$ logic. Descartes can claim that the most that can be reasonably demanded is a clear and distinct perception which is clearly and distinctly perceived to yield the truth, or in other words a clear and distinct perception that is analogous to $G-L$ provability. What is good enough for $G-L$ logic must be good enough for Cartesian metaphysics. Descartes lived before our age of conceptual turmoil and did not have a reason to anticipate it, but by taking the deflationary meditational or confessional approach, Descartes wisely and humbly concedes that in an encounter with radical skepticism the best to be hoped for is a more modest form of clear and distinct perception, which does not pretend guarantee truth and thereby validate an epistemological claims on others. The Cartesian consolation is that one of the causes of all the conceptual turmoil of the last century also prompted a logic that accommodates the need for an analogous deflationary view of provability in mathematics. All that brings us to the last word, from Descartes' point of view. True, we are now satisfied with provability in mathe-

\footnotetext{
${ }^{9}$ Anyway, don't some of our own principles of physics and metaphysics seem to defy "common sense" to the point of unintelligibility?
} 
matics and not by clear and distinct perception in metaphysics, but the question that arises is this: Just how are we supposed to satisfy ourselves of provability in mathematics except by clear and distinct perceiving that we have clearly and distinctly perceived each step, of each putative proof, beginning with clear and distinct intuitions and progressing step by step by clear and distinct reasoning?

\section{Limitations and Future Research}

The principal limitations of the approach that this paper has taken point to opportunities for further research. First, as I have acknowledged, the paper does not put us in a firm position to defend Descartes' substantive at this point in time. To the extent that we deny the possibility of a priori knowledge we shall find the Cartesian point of view implausible. Yet, methodological convictions, about how to proceed in logic and philosophy, are not contingent claims, and I believe that this paper has shown that to the extent that Cartesian methodology can be defended, radical doubt can be dispelled. Secondly, the first personal component of $\boldsymbol{D C}_{i}$ suggests that when confronting metaphysical doubt (that is, assuming that one puts oneself in Descartes' place), each individual needs to satisfy herself or himself about how far the limitations of provability in PA should be allowed to extend in undermining one's own methodological convictions. In particular, the deep question in light of current thinking about the foundations of knowledge, particularly mathematical knowledge, is: Just how confident can we be about the Truth Rule in light of current developments especially in mathematics and mathematical physics?

\section{References}

Arnauld, A. (1641). Fourth Set of Objections and Replies. In Cottingham et al. (Eds.), The Philosophical Writings of Descartes (pp. 138-198, Vol. 2). Cambridge: Cambridge University Press.

Burman, \& Descartes (1648). Descartes' Conversation with Burman. John Cottingham, Trans. 1976, Oxford: Clarendon Press.

Cottingham, J., Stoothoff, R., \& Murdoch, D. (1985). The Philosophical Writings of Descartes (Vol. 1 and 2). Cambridge: Cambridge University Press.

Cottingham, J. (1992). The Cambridge Companion to Descartes. Cambridge: Cambridge University Press.

Descartes (1641). Meditations on First Philosophy. In Cottingham et al. (Eds.), The Philosophical Writings of Descartes (pp. 1-52, Vol. 2). Cambridge: Cambridge University Press.

Descartes (1637). Discourse on Method: Part One. In Cottingham et al. (Eds.), The Philosophical Writings of Descartes (pp. 11-16, Vol. 1). Cambridge: Cambridge University Press.

Gassendi, P. (1641). Fifth Set of Objections and Replies. In Cottingham et al. (Eds.), The Philosophical Writings of Descartes (pp. 179-277, Vol. 2). Cambridge: Cambridge University Press.

Loeb, L. (1992). The Cartesian Circle. In Cottingham, J. (Ed.), The Cambridge Companion to Descartes. Cambridge: Cambridge University Press.

Malcom, N. (1959). Dreaming, (pp. 101-108). London, Routledge \& Kegan Paul.

Van Benthem, J. (2010). Modal Logic for Open Minds (pp. 243-250). Stanford, CA: CSLI 
Publications.

Williams, B. (1978). Descartes: The Project of Pure Inquiry (pp. 72-101). New York, NY: Penguin.

Wilson, M. (1978). Descartes (pp. 1-78). London: Routledge \& Kegan Paul. 


\section{Appendix A: A Reconstruction of Descartes' Argument for the Existence of God in Meditation III}

1) I have a clear and distinct idea of God, autobiographical report viz, an idea of an eternal, simple, self-caused object.

2) I have an idea of a being who is God if and only if it is simple, eternal and self-caused. In other words my idea of $\mathrm{x}$ is an idea of God and if only if my idea of $x$ is an idea of a being who is simple, eternal and self-caused. (interpretation of 1)

3) Ex nihilo, nihilo fit. (clear and distinct metaphysical principle)

4) The cause of a thing explains its existence and identity. (definitional)

5) The identity of an idea is determined by what it is an idea of. (definitional)

6) Whatever causes an idea explains what it is an idea of. $(4,5)$

7) Whatever explains the identity of an idea must "have as much reality as the object of the idea". (3.6)

8) The only object with "as much reality" as an eternal object is an eternal object. (clear and distinct metaphysical principle)

9) The cause of the idea of God is eternal. $(2,7,8)$

10) Necessarily, nothing eternal was created. (definitional)

11) Nothing external to an eternal object can cause it that is is, can create it). (10, definitional)

12) Everything has a cause. (4)

13) Every cause is internal or external. (definitional)

14) The cause of an eternal object is internal, which is to say that every eternal object is "self-caused". (11, 12, 13, definitional)

15) The cause of the idea of God is self-caused. $(9,14)$

16) Necessarily, anything eternal cannot be destroyed. (definitional)

17) Whatever cannot be destroyed does not have parts; i.e. i.e., is simple. (clear and distinct metaphysical principle)

18) The cause of the idea of God is simple. $(9,16,17)$

19) The cause of the idea of God is eternal, simple and self-caused. $(9,15,18)$

20) The idea of God as a simple, eternal, self-caused being is clear and distinct. (1)

21) Every clear and distinct idea is true. (The Truth Principle)

22) A being is God if and only if that being is simple, eternal and self-caused. $(20,21)$

23) The cause of the idea of God is God. $(19,22)$

24) Anything that causes something to exist also exists (albeit at least at its "level" of reality). (3)

25) The cause of the idea of God exists. $(1,24)$

26) God exists. $(22,25)$

\section{Appendix B: The Truth Rule}

$\mathrm{T}$ : (Abbreviation of the Truth Rule): If I clearly and distinctly perceive that $\mathrm{P}$, then $\mathrm{P}$ is true. 
D: (Definition of Clearly and Distinctly Perceiving): I clearly and distinctly perceive $\mathrm{P}$ if and only if I believe that $\mathrm{P}$, and $\mathrm{P}$ is "unshakable" for me. (from Loeb)

$\mathrm{U}$ : (Definition of Unshakable for $\mathrm{X}$ ): $\mathrm{P}$ is unshakable for $\mathrm{X}$ if and only if $\mathrm{X}$ has arguments that make it impossible for any argument to dislodge $\mathrm{X}$ 's belief that $\mathrm{P}$, that is, make it impossible for any argument to count as a reason against $\mathrm{P}$ for $\mathrm{X}$. (from Loeb ${ }^{10}$ )

$\mathrm{A} 1: \mathrm{A}$ is the assumption that from 1 ) If $\mathrm{X}$ clearly and distinctly perceives IF $\mathrm{P}$, THEN Q, and 2) X clearly and distinctly perceives $\mathrm{P}$ we may validly infer 3) $\mathrm{X}$ clearly and distinctly perceives $\mathrm{Q}$.

A2: If I clearly and distinctly perceive that $\mathrm{P}$ true, then $\mathrm{P}$ is "necessarily true each time I conceive it or put it before my mind."

A3. If an argument counts for me as an argument against $\mathrm{P}$, then it counts for me as an argument in favor of NOT-P.

Preliminary Proof of P5 (below): There isn't any argument that would count against the Truth Rule, $\mathrm{T}$, for me.

P1. Suppose that argument A counts as a reason for me against the Truth Rule.

P2. Then A counts as a reason for me against the claim that IF I clearly and distinctly perceive $\mathrm{T}$, THEN $\mathrm{T}$ is true. $(\mathrm{P} 1, \mathrm{~T})$

P3. Thus, A counts as a reason for the conjunction: 1) I believe that $\mathrm{T}, 2) \mathrm{T}$ is unshakable for me and, yet, 3 ) $\mathrm{T}$ is not true. (P2, A3)

$\mathrm{P} 4$. But no argument can count as a reason for me in favor of 1), 2) and 3) (P3 above) because any argument that counts for me in favor of 2) is an argument that makes it impossible for any argument to count for me as a reason against $\mathrm{T}$ and hence against 3). In other words, if A counts as a reason for me for the unshakability of $\mathrm{T}$, it also rules out for me any argument against the truth of T. (P3, U)

P5. Hence, it is impossible that A counts for me as a reason against the Truth Rule. (P4, T)

Claim C7 (below): I clearly and distinctly perceive that $\mathrm{T}$ is true.

Claim C8 (below): $\mathrm{T}$ is necessarily true each time I conceive it or put it before my mind.

$\mathrm{C} 1$. There isn't any argument that would count against $\mathrm{T}$ for me. (P5)

C2. Therefore, $\mathrm{T}$ is unshakable for me. (1 and $\mathrm{U}$ )

C3. I believe T. (autobiographical report)

C4. Therefore, I clearly and distinctly perceive T. (C2, C3, D)

C5. Therefore, I clearly and distinctly perceive that whatever I clearly and distinctly perceive is true. (instantiation of $\mathrm{T}$ in $\mathrm{C} 4$ )

C6. Therefore I clearly and distinctly perceive that if I clearly and distinctly perceive $\mathrm{T}$, then $\mathrm{T}$ is true. (instantiation of $\mathrm{T}$ in $\mathrm{C} 5$ )

\footnotetext{
${ }^{10}$ This treatment of clear and distinct perception is inspired by Loeb. See: (Loeb/Cottingham, 1992: pp. 200-236; especially pp. 203-206). This type of treatment was suggested earlier in (Williams, 1978: pp. 130-163; especially pp. 147-153). Sill earlier, Norman Malcolm also develops the idea of incorrigibility in his Dreaming, (Malcolm, 1959: pp. 101-108).
} 
C7. Hence I clearly and distinctly perceive that $\mathrm{T}$ is true. $(\mathrm{C} 4, \mathrm{C} 5, \mathrm{~A} 1)$

$\mathrm{C} 8$. Hence $\mathrm{T}$ is necessarily true each time I conceive it or put it before my mind. (C7, A2)

It would appear that $\mathrm{C} 8$ certifies $\mathrm{T}$ by Cartesian standards for use in dispelling doubt, because the "cogito" is likewise "certified" (clearly and distinctly perceived) by virtue of the fact that it is "necessarily true each time I conceive it or put it before my mind." T can be therefore used to prove that God exists and is not a deceiver, which proposition guarantees that everything that is clearly and distinctly perceived by me to be true really is true. Of course, $\mathrm{T}$ can be used in proofs only by those who are satisfied to use in proofs what is beyond their own doubt; that is, certified. But the question is nonetheless whether or not clear and distinct perception actually does certify.

Submit or recommend next manuscript to SCIRP and we will provide best service for you:

Accepting pre-submission inquiries through Email, Facebook, LinkedIn, Twitter, etc. A wide selection of journals (inclusive of 9 subjects, more than 200 journals) Providing 24-hour high-quality service User-friendly online submission system Fair and swift peer-review system Efficient typesetting and proofreading procedure Display of the result of downloads and visits, as well as the number of cited articles Maximum dissemination of your research work

Submit your manuscript at: http://papersubmission.scirp.org/ Or contact ojpp@scirp.org 